\title{
Microseismic Monitoring of Open Pit Slopes
}

\author{
R.A. Lynch, R. Wuite, B.S. Smith, A. Cichowicz \\ ISS International Limited, South Africa
}

Since slope angles are critical to the economics of open pit mining, microseismic monitoring of fracturing within a slope can add significant value. Recent technological advances have enabled the routine use of this technique, yielding three-dimensional quantitative information about the state of the slope. A simple numerical model has been constructed of an open pit slope and the results are discussed in light of the fact that recorded seismic events can be located some hundreds of meters behind the slope surface. Seismic movements of known geological structures within the slope can be recorded and potentially used to assess trends in relative stability. It should be possible to indicate previously unknown structures using microseismic data, which may then be confirmed by other geotechnical techniques. The effects of complex geology and geometry on recorded seismic data have been studied and a composite focal mechanism method has been used to constrain possible fault plane orientations. Appropriate source spectral models for open pit seismic events have been discussed. Two case studies show that surface movements inferred from microseismic data enjoy a close spatial correlation with actual surface movements, with an advance indication of some 30-45 days. The paper shows that carefully analysed microseismic data from open pit slopes can be used to gain greater insight into the effects of mining and subsequently can result in more accurate assessments of slope stability.

\section{INTRODUCTION}

In open pit mining it is important to carefully monitor especially high and/or steep slopes for indications of impending failure. This is particularly true since many high slopes are now being designed with a managed risk approach, in which slope failures can be tolerated as long as miner safety is not compromised.

Slope monitoring is normally carried out using surface deformation measurements of either points on the surface or the entire surface. However it can be difficult to identify future potential failure mechanisms from the 1- or 2-dimensional surface data, no matter how accurately such data is being obtained.

Brittle fractures in rock radiate seismic waves. If these waves can be recorded sufficiently clearly as seismograms by a number of sensors, the seismic event's origin time, location and source parameters such as radiated seismic energy and inelastic coseismic deformation can be estimated. While the technique is commonplace in underground mining operations (see for example Mendecki et al., 1997 or van Aswegen et al., 2000), it is only recently that technological advances have enabled routine microseismic monitoring in the open pit environment. Seismic events can now be located and quantified in the 3-dimensional volume of the rock slope, opening the door to a deeper understanding of how mining is affecting the slope.

Measurements have been taken at more than 15 open pit slopes to date and all contain signatures of brittle rupturing. In one case, a slope height of $80 \mathrm{~m}$ was enough to generate recordable microseismicity. In another, a soft wet rock slope with intact UCS values of 20-50 MPa was also causing recordable microseismicity. These extreme cases might indicate that routine microseismic monitoring is possible in most open pit slopes.

This paper sets out to present an overview of the work being done on open pit seismic monitoring by ISS International. Topics discussed include implementation of seismic monitoring in open pits (section 2), an understanding of the mechanisms of microseismicity in this environment using simple numerical models (section 3) and planes of weakness found in the seismic data (section 4), analyses of open pit seismograms in terms of amplitude, frequency spectra, possible focal mechanisms (section 5) and frequency decay (section 6) as well as analyses of the recorded microseismicity compared with mining activities and surface deformation of the slopes (section 7). Some of the analysis techniques are already being used routinely (particularly those of section 7), while others are still being investigated.

\section{ROUTINE MICROSEISMIC MONITORING IN THE OPEN PIT ENVIRONMENT}

Microseismic monitoring has been attempted several times in the open pit environment in the past, without much success. The major stumbling block has been a lack of suitable equipment. Recently low power GPS receivers and low power highly efficient embedded processors have become available. This has allowed intelligent seismic stations with less than $3 \mathrm{~W}$ power consumption to be powered by small solar panels. Signals from the tri-axial seismic sensors are recorded as seismograms and either stored locally on hard disk for later retrieval or transmitted to a central computer via digital radios.

The kind of fast internet connections commonly found on mines these days allow the seismic data to be automatically sent to a remote central facility for processing and analysis. For each seismic event the origin time, spatial location and estimates of the source parameters are computed. After routine analysis of the seismic event data, regular reports are then sent back to the mine geotechnical engineers for interpretation along with other geotechnical data.

\subsection{Navachab Mine, Namibia}

The Navachab gold mine is situated near the town of Karibib, about $200 \mathrm{~km}$ east of Swakopmund in Namibia, southern Africa. After a small slope failure at the mine in early 2000, faint popping noises in the slope during the quiet period 
after blasting were cause for concern. Some preliminary seismic measurements were conducted in August 2001 and a small permanent system was installed in February 2002 for routine monitoring of microseismic activity behind the eastern highwall. To the best of our knowledge, Navachab is the first open pit mine in the world to successfully implement routine microseismic monitoring.

The seismic system consisted of two StandAlone QS data loggers (ISSI, 2001) monitoring four tri-axial seismic sensors. The sensors are arranged in a tetrahedral configuration within the slope. Sensors 1 and 2 were installed in an existing vertical exploration hole drilled from just outside the central eastern side of the pit. Sensors 3 and 4 were installed at each end of the $1050 \mathrm{~m}$ berm (catchment bench), about half-way down the pit slope. A volume of about $300 \mathrm{~m}$ by $180 \mathrm{~m}$ by $150 \mathrm{~m}$ was being monitored. Fig. 1 indicates the positions of the sensors.

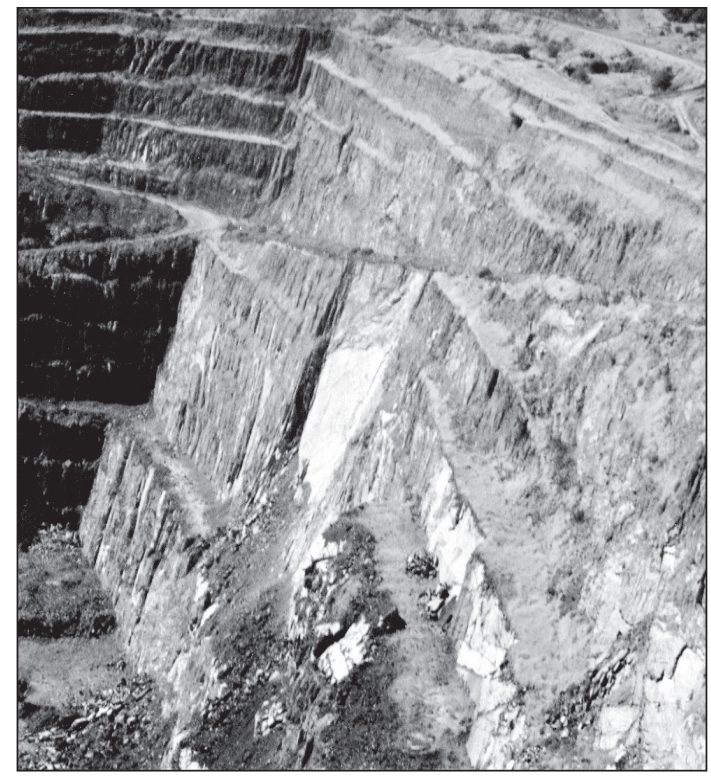

FIG. 1 The eastern slope of Navachab gold mine in Namibia. The area of a small laminar failure in early 2000 is visible. The pit depth was approximately $160 \mathrm{~m}$ when this photograph was taken

The StandAlone QS (SAQS) data loggers operated in an off-line mode, with seismograms being stored locally on removable hard disks for later retrieval and download. The use of internal GPS receivers ensured common time between the two seismic stations.

In April 2004 an enlarged microseismic array was installed. This array consists of 8 tri-axial seismic sensors and monitors a volume of rock some $500 \mathrm{~m}$ by $300 \mathrm{~m}$ by $250 \mathrm{~m}$. Digital radios with a repeater station are used for real-time monitoring. Regular data processing, analysis and reporting is done at ISSI's facility in Stellenbosch, South Africa. This kind of microseismic system, with sensors installed in long boreholes drilled from outside of the pit, solar-powered SAQS data loggers and routine remote processing and analysis of seismic data, is now in use at other open pit mines in South Africa and Australia.

\subsection{Union Reefs Mine, Australia}

Union Reefs gold mine is located in the Northern Territories in Australia, approximately $300 \mathrm{~km}$ south of Darwin. The mine has a number of pits, including the Crosscourse pit. Mining ceased here in June 2002 and all de-watering activities around the pit were stopped. A potential failure was identified on
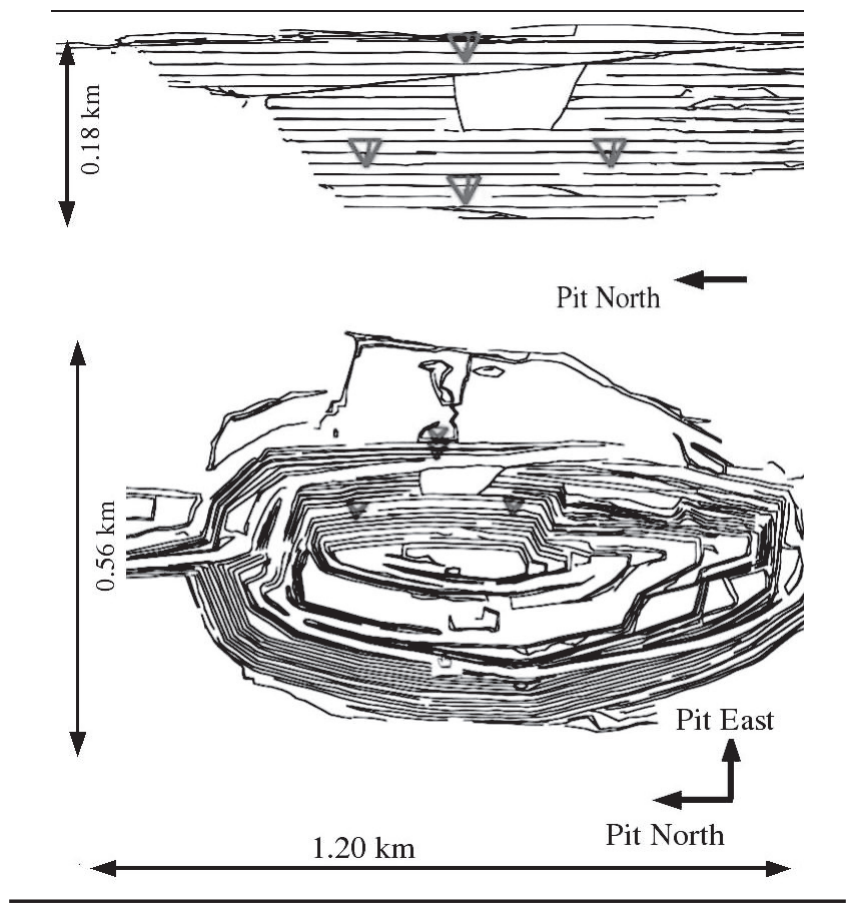

FIG. 2 Side (looking east) and plan views of the initial microseismic network installed at Navachab. The tri-axial seismic sensors are shown as red triangles

the north-western slope and this area was instrumented with 6 tri-axial seismic sensors, installed into 4 boreholes drilled from outside the pit.

Microseismicity was monitored by 3 StandAlone QS data loggers for a 6-month test period, during which the wall was anticipated to fail. Seismograms were stored on removable hard disks, which were processed and analysed off-line. Solar panels were used to power the SAQS data loggers.

While the wall did not fail during this experiment, interesting seismic data was recorded and is presented in section 6 .

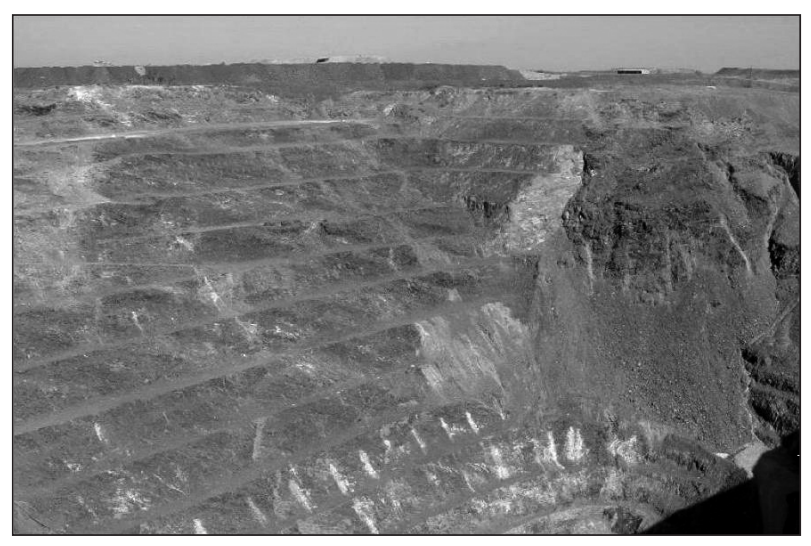

FIG. 3 The western slope of the crosscourse pit at Union Reefs gold mine, Australia. The wall was instrumented with 6 tri-axial seismic sensors and monitored from May to December 2002 in an AngloGold Australasia-sponsored experiment

\subsection{Potgietersrust Platinum Mine, South Africa}

The Sandsloot pit of Potgietersrust Platinums Limited is located near the town of Mokopane, north of Johannesburg in South Africa. The seismic array consists of 4 tri-axial seismic sensors and two SAQS units and was installed in August 
2003 to monitor a particular structure in the eastern slope. Approximately 1800 seismic events triggering at least 1 sensor are recorded here every month. These events have typical log (potency) in the range -5 to -2 (moment magnitudes from -2.5 to -0.5$)$.

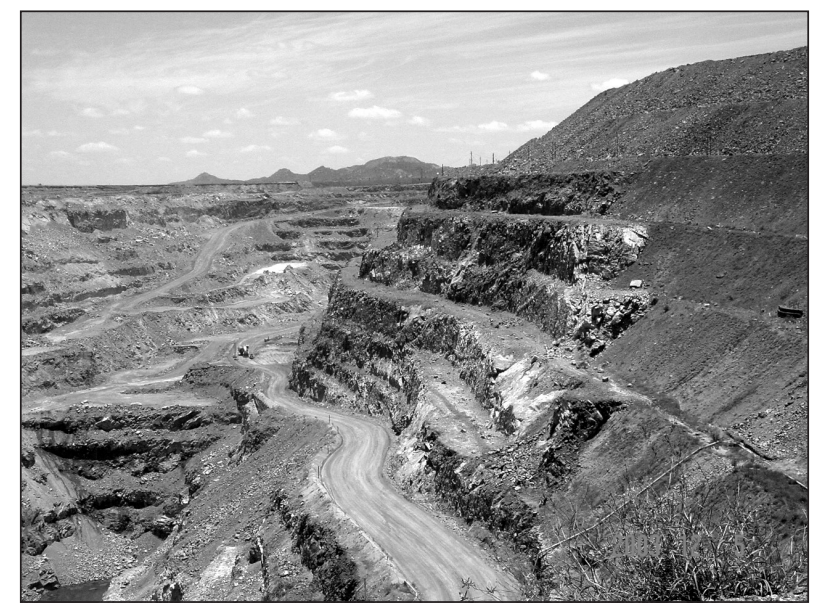

FIG. 4 The eastern slope of the Sandsloot pit, Potgietersrust Platinums Limited. A permanent microseismic system was installed here in August 2003

\section{COMPARISONS OF SEISMIC DATA WITH NUMERICAL MODELLING AT NAVACHAB}

During May to December 2002, approximately 450 seismic events were recorded behind the eastern slope of Navachab mine. The depths of the located seismic events vary from a few meters behind the highwall to as much as about $200 \mathrm{~m}$. The location errors of these events are of the order of 10-20 m, with $\log$ (potency) in the range -4 to -1 (moment magnitudes in the range -2 to 0 ).

The side view in Fig. 5 shows that the seismic events are being recorded mainly at the bottom of the eastern slope, as expected.

To better understand the origin of the recorded microseismicity, a simplified elastic numerical model of the eastern Navachab wall was constructed using FLAC2D (Itasca, 2000). Plane strain conditions are assumed, so there are out-of-plane stresses, but not strains (Popov, 1990). The material constants used were obtained from the mine geotechnical engineer and are:

Young's modulus: $\mathrm{E}=80 \mathrm{GPa}$

Poisson's ratio: $v=0.254$

Density: $\rho=2900 \mathrm{~kg} / \mathrm{m}^{3}$

The ratio of horizontal to vertical in situ stresses, $\mathrm{K}$, was assumed to be in the range 2-3. Furthermore the maximum principle stress was assumed to be horizontal east-west.

Following Stacey et al. (2003a) and Popov (1990), extension strain is defined as the minimal principal strain $\varepsilon_{3}$ (in a positive compressive convention) and is calculated from the principle stresses using the three dimensional elastic equation:

$$
\varepsilon_{3}=\frac{\left[\sigma_{3}-v\left(\sigma_{1}+\sigma_{2}\right)\right]}{E}
$$

where $\sigma_{1}, \sigma_{2}$ and $\sigma_{3}$ are the principle stresses directions with $\sigma_{1}>\sigma_{2}>\sigma_{3}$.

If a zone of extension strain is present in a material then the material will be expanding in at least in one direction in that zone. Extension strain values must be at least of order $10^{-4}$ for fracture of intact brittle rock to occur at Navachab (Stacey
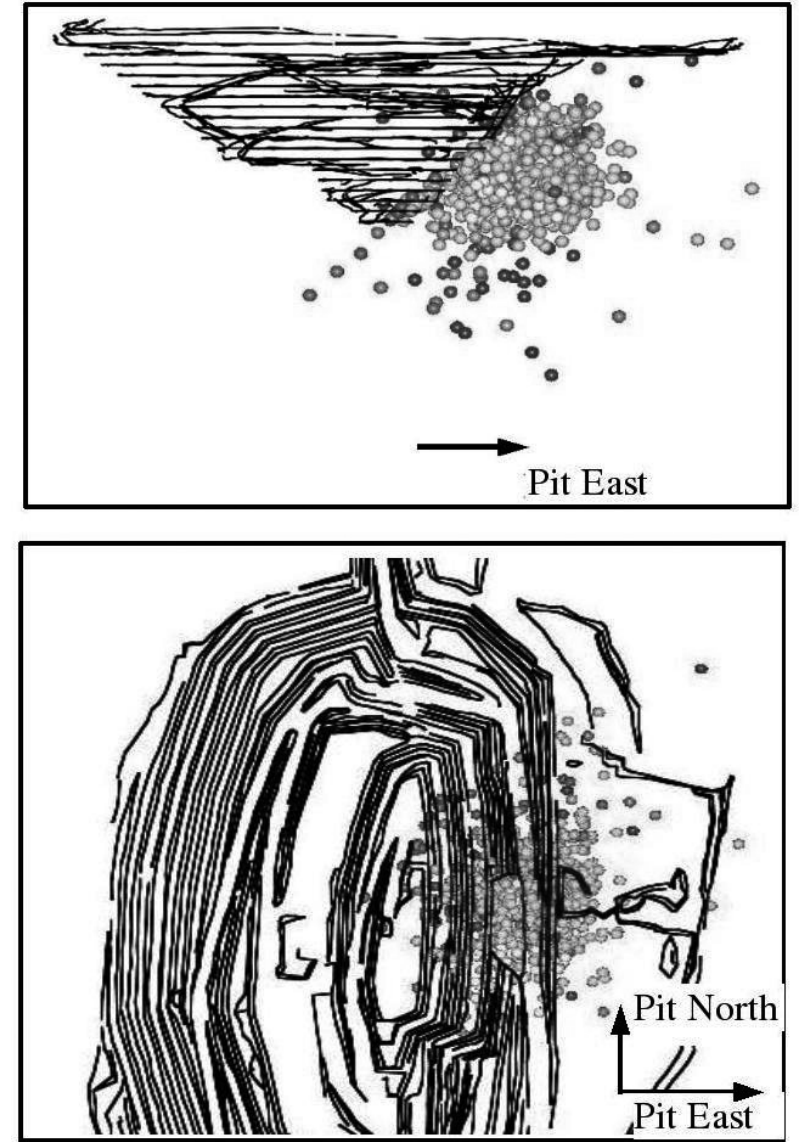

FIG. 5 Side (looking north) and plan views of the spatial distribution of seismic events recorded from May 2002 to November 2003

et al., 2003b), where the UCS of the intact rock is about $120 \mathrm{mPa}$. Such brittle fractures would be predominantly tensile in nature and could be recorded as seismic events.

Contours of extension strain calculated for the Navachab mine FLAC model are plotted in Fig. 6. It is evident from this that the magnitude of the largest values of extension strain are an order of magnitude lower than that required for brittle fracturing in an isotropic homogenous rockmass. This does not change significantly with K-ratios between 2 and 3 . The zone of extension strain exceeding $2.5 \times 10^{-5}$ extends horizontally to approximately $40 \mathrm{~m}$ behind the pit wall toe. The general shape and location of these zones are consistent with regions of recorded microseismicity - see Fig. 5.

An accepted method of calculating the stability of open pit slopes using finite difference modelling packages is by reducing the shear strength parameters of the rock in stages until the pit fails (Sainsbury et al., 2003). The accumulation of shear strain in the rockmass behind the pit wall can be considered a mechanism of shear brittle failure. A plot of maximum shear strain is shown in Fig. 7.

Fig. 7 illustrates that, other than a very small region at the toe of the slope, maximum shear strain is also not large enough to cause brittle shear failures of intact rock. However, it must be noted that the zones of maximum shear strain also extend quite deeply into the slope. The horizontal extent of the $2.5 \times 10^{-5}$ contour is about $100 \mathrm{~m}$.

Since the shear strain and extension strain zones overlap near the bottom of the slope, brittle fractures here would be combinations of tensile and shear behaviour. Deeper into the slope, shear-type fractures would be more common. 


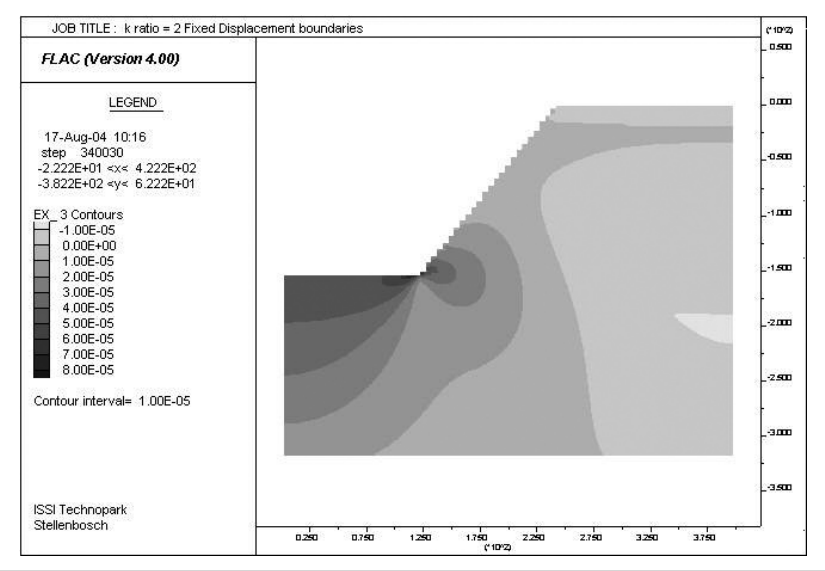

FIG. 6 Contours of extension strain obtained from the simplified 2D FLAC model of the eastern wall, for a K-ratio of 2 . No significant extension strain fracturing zones are obtained

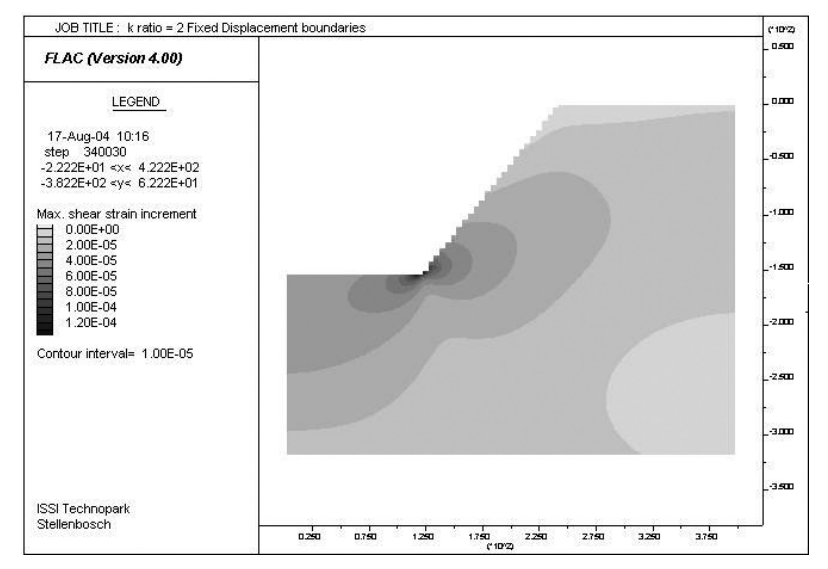

FIG. 7 Contours of maximum shear strain obtained from the simplified 2D FLAC model. No significant zones of shear strain exceeding $10^{-4}$ are obtained

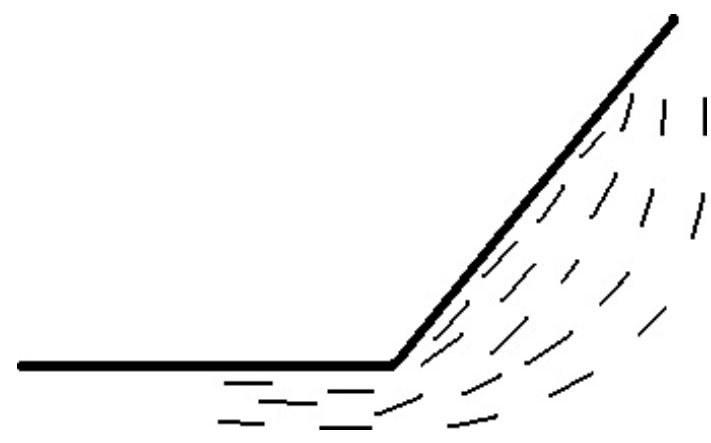

FIG. 8 Probable fracture orientations, based on major principal stress directions for the simplified 2-D elastic

Fig. 8 shows the probable fracture orientations, indicated by the principal stress directions, for extension strain from the simple numerical model. The orientations of these fractures near the bottom of the slope are sub-parallel to the slope surface.

The magnitude of both shear strain and extension strain in the idealised case indicates that brittle fracturing of an isotropic homogenous rockmass is not likely, since the maximum values do not exceed $10^{-4}$. Stacey et al. (2003) have indicated that a slope of at least $400 \mathrm{~m}$ in height and an in situ $\mathrm{K}$ ratio of larger than 2 is needed for extension strain to exceed critical values here.
However the fact that microseismicity is actually being recorded here indicates that geological structures are playing an important role. The major structures in this part of the Navachab pit are the J1 joint set. These bedding planes are roughly parallel to the slope surface, dipping at $45^{\circ}-55^{\circ}$. This coincides with the most likely fracture orientations in Fig. 8 and thus is probably the mechanism for the recorded seismic events. A more sophisticated model should take this into account, but was not required for this investigation.

\section{PLANes OF WeAKNess from SEISMic data}

It would be useful to know if particular planes of weakness were being indicated by recorded microseismic data. To investigate this, a simple plane-detection algorithm was developed. The space of all possible planes passing through at least one of the seismic events is discretised and each possible plane is assigned a rank based on the number of seismic events, $n$, located within some distance of it. The natural 'thickness' of the plane is the seismic event location accuracy, which is indicated from the residuals of the $1^{\text {st }}$ norm location inversions. In this way the average number of seismic events per plane, $n_{\text {ave }}$ and the standard deviation $\sigma_{n}$ can be estimated. Any plane with $n>n_{\text {ave }}+3 \sigma_{n}$ is statistically significant to within a $99.7 \%$ confidence interval.

During October 2002 a burst of microseismic activity occurred in the Navachab eastern slope. This activity is related to significant movement of the wall (see section 7 of this paper) and is therefore interesting to search for planes of weakness.

The most statistically significant plane found in this data is shown in Fig. 9. This plane is a dip direction azimuth of $261^{\circ}$ and a dip angle of $40^{\circ}$. This is very similar to the J1 joint set at Navachab, with dip direction azimuths of $280^{\circ} \pm 10^{\circ}$ and dip angles of some $45^{\circ}$ to $55^{\circ}$. Thus it would appear that this bedding plane was delaminating to some degree during this period. Indeed, the 2-dimensional numerical modelling results presented in section 3 indicated that this orientation would be preferred for fracturing.

\section{WAVEFORM AND SPECTRAL ANALYSIS OF SEISMIC DATA RECORDED AT NAVACHAB}

\subsection{Seismic Data and Velocity Model}

The data set used in this section comprises seismic events that were recorded by the extended array at the Navachab Gold Mine. The array consists of 8 tri-axial seismic sensors. Since the installation of this array, the largest recorded events have only triggered 7 of the 8 sensors. The array records an average of 600 events per month. After processing, we observe that most of the 3- and 4- seismogram events tend to locate within the vicinity of the array, whereas the 6- and 7- seismogram events tend to locate outside of the array, near the bottom of the pit. Between May 2004 and July 2004 the moment magnitude range for the events is about -2 to 0 .

Shortly after the installation of the wireless network at Navachab, four calibration blasts were performed to determine the seismic wave velocities. Three of these blasts occurred in the oxidised schist rock layer of the pit and the fourth was at a depth of approximately $60 \mathrm{~m}$ below surface, at the interface between the upper oxidised schist and lower fresh schist layers. From these blasts the P- and $\mathrm{S}$-wave velocities for the fresh schist layer were found to be $V_{p}=6300 \mathrm{~m} \cdot \mathrm{s}^{-1}$ and $V_{\mathrm{s}}=3700 \mathrm{~m} \cdot \mathrm{s}^{-1}$ respectively. These values are in fair agreement with velocities calculated using laboratory results for density $\left(2900 \mathrm{~kg} \cdot \mathrm{m}^{-3}\right)$, Poisson's ratio (0.254) and Young's Modulus (80 GPa). These velocities were calculated to be $V=5800 \mathrm{~m} \cdot \mathrm{s}^{-1}$ and $V=3300 \mathrm{~m} \cdot \mathrm{s}^{-1}$ for the fresh schist layer. The velocities used in processing seismic data from Navachab are those obtained from the calibration blasts. 
Since these velocities are specific to the fresh schist layer, they do not assist in an accurate location for seismic events that occur within the oxidised schist layer. However, this is not of concern since most of the recorded seismic events locate within the deep fresh schist layer. To improve the location of the processed seismic events, the velocity model includes a correction at the seismic sensor that takes into account the rock layer in which it is located.
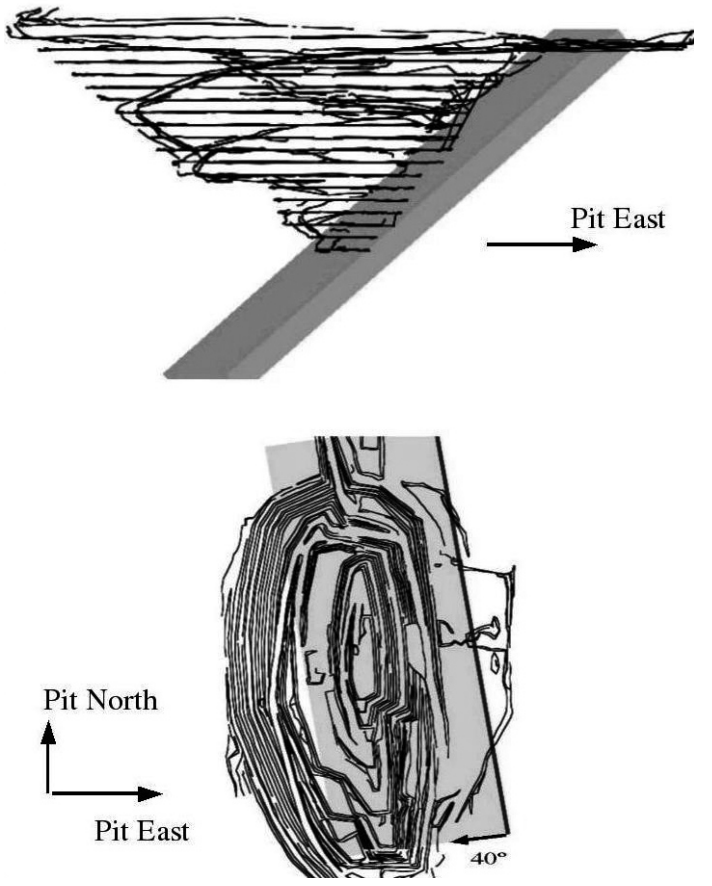

FIG. 9 The most statistically significant plane found in the seismic data from May 2002 and November 2003

\subsection{Interpretation of Seismograms}

Analysis of the seismic wave propagation at Navachab was performed on a data set consisting of seismic events that triggered at least 4 sensors. The seismic waves generated by these events traverse and span an extensive volume of rock. Analysis of these waveforms gives a better understanding of how the waves behave as they traverse different rock layers. A seismic event was recorded on 21 July 2004 with peak ground velocity (PGV) in the range $1.2 \times 10^{-6}$ to $7.0 \times 10^{-6} \mathrm{~m} . \mathrm{s}^{-1}$. The event triggered 7 of the 8 seismic sensors (site ID's 15, 14, $13,12,11,8$ and 6). Sensors 15, 13, 12 and 11 are located deep within the fresh schist layer, whilst sensors 6,8 and 14 are located close to a free surface of the pit - see Fig. 10.

We observe attenuation of the body wave signal with an increase in distance from the source. Most of the deeper sensors (site ID's 15, 13, 12 and 11) record simple and clear waveforms, whereas the sensors that are located closer to a surface (site ID's 6, 8 and 14), record several strong pulses after the S-wave arrival. We interpret this feature as a surface wave. Fig. 10 illustrates the dominant pulses after the S-wave arrival, especially on the sensors that locate close to a surface. Further analysis has shown that this feature is present in most of the recorded data at Navachab. Apart from the strong pulses after the S-wave arrival, the surface wave manifests itself as a peak in the spectrum between $10-30 \mathrm{~Hz}$ (see Fig. 10). The spectral content of this feature combined with its frequent occurrence throughout our dataset suggests that it should not be treated as a source parameter, but instead probably a consequence of the geometrical structure and complexity of the pit.
We observe that the duration of the direct P-wave increases with an increase in distance from the source. The duration of the S-wave group appears to decay with an increase in distance from the source for deeper sensors. This feature was made apparent on inspection of several events. All the waveforms have a stronger group of S-waves than P-waves; however, the surface waves have a much weaker effect on seismograms that were recorded by the deeper sensors. Notice that the z-component of the seismogram recorded by sensor 11 has several strong pulses after the S-wave arrival despite the fact that this sensor was furthest from the event $(466 \mathrm{~m})$ and is located approximately $200 \mathrm{~m}$ from the nearest free surface.

Fig. 10 shows that the signal recorded by sensor 11 arrived earlier than the theoretical arrival time. This could be explained by the location of the sensors. Propagation of seismic waves through the competent rock is expected to be faster than the apparent velocity of the network. Since sensor 11 is located deeper into the fresh schist layer of the rockmass, this would explain the earlier arrival.

\subsection{Spectral Parameters}

Spectral parameters are routinely calculated from the P- and $\mathrm{S}$-wave groups. In most cases, this method of determining spectral parameters is hampered by (a) the time separation between the P- and S-wave arrival being too short and thus, the P- wave spectra can not be calculated and (b) the group of the S-wave often contains the dominant surface wave phenomena, thus preventing the easy analysis of the S-wave spectra.

Fig. 11 is the stacked spectra for the seismograms illustrated in Fig. 10. All individual spectra in the stacked spectrum have been corrected for distance. If the spectrum in Fig. 11 is used to calculate source parameters, the Brune (solid smooth fit) model fit is obtained (Brune, 1970). The Brune fit to the spectra is made to the surface wave and body wave contributions and therefore results in the spectrum level being over estimated. The spectrum in Fig. 11 illustrates amplification in the $10-30 \mathrm{~Hz}$ frequency band, which is a result of the contributions from all sensors, but especially sensors 8 and 14. The surface wave effect is present in all seismograms, but stronger in those from shallower sensors. From Fig. 11 the following parameters were obtained from the Brune spectral fit: seismic moment $=9.9 \times 10^{7} \mathrm{Nm}$, static stress drop $=0.2 \times 10^{5} \mathrm{~Pa}$ and the corner frequency $=18 \mathrm{~Hz}$. Using this seismic moment, the moment magnitude is calculated to be -0.7 .

If the effects of the surface wave are ignored from the spectrum, the solid black line would represent the spectral level. In order to obtain the source parameters from the spectra, we observe the decay in the spectrum starting between $80 \mathrm{~Hz}$ $-100 \mathrm{~Hz}$. We selected this range for the corner frequency of the body wave and the corresponding spectrum level, $10^{-8} \mathrm{~m}^{2} \mathrm{~s}$, as the correct source parameters. This spectrum level corresponds to a seismic moment of $2.8 \times 10^{7} \mathrm{Nm}$, equivalent to a moment magnitude of approximately -1.0 .

In order to confirm our estimation, the corner frequency was also estimated using the duration of the direct P- wave pulse $(0.01 \mathrm{~s}$, or $100 \mathrm{~Hz})$. Using this data the source radius was estimated to be approximately $10 \mathrm{~m}$.

\subsection{A Seismic Event Located Far from a Free Surface}

Seismograms that are recorded by seismic sensors deep within the rockmass and far from any free surfaces of the pit are less likely to have a strong effect from the surface waves. In these instances the strong pulses after the S-wave arrival are not present and the source parameters corresponding to such seismograms can be estimated more reliably from the stacked spectrum. 


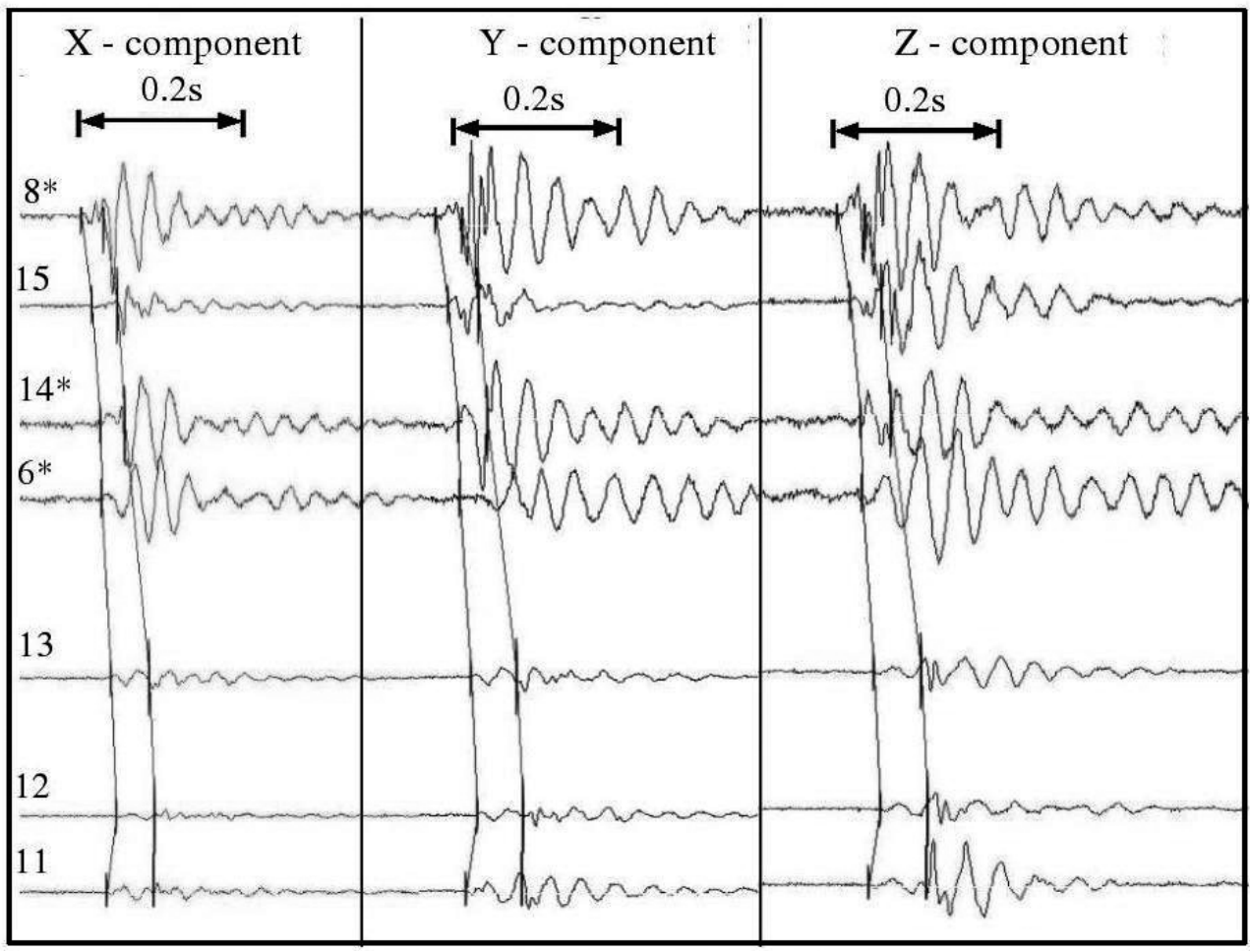

FIG. 10 The travel time graphs of a seismic event recorded on 21 July 2004. The first vertical bar drawn on the seismogram marks the P- wave arrival and the second marks the S-wave arrival. The line joining these vertical bars illustrates the actual travel time of the event. The site ID's of the sensors are located on the left of the illustration, with shallow sensors marked with *. The seismograms are arranged in descending order of distance from the source: $(8,256 \mathrm{~m}),(15,289 \mathrm{~m}),(14,321 \mathrm{~m}),(6,344 \mathrm{~m}),(13,399 \mathrm{~m}),(12$, $446 \mathrm{~m})$ and $(11,466 \mathrm{~m})$ with the following peak particle velocities [mm.s $\left.\mathrm{s}^{-1}\right]:\left(8,5.8 \times 10^{-3}\right),\left(15,3.0 \times 10^{-3}\right),\left(14,4.3 \times 10^{-3}\right),\left(6,3.4 \times 10^{-3}\right)$, $\left(13,9.4 \times 10^{-4}\right),\left(12,7.9 \times 10^{-4}\right)$ and $\left(11,2.2 \times 10^{-3}\right)$

Fig. 12 shows just two seismograms from an event that was recorded on the 21 July 2004, with peak ground motion in the range $1.9 \times 10^{-6} \mathrm{~m} \cdot \mathrm{s}^{-1}$ to $8.1 \times 10^{-6} \mathrm{~m} \cdot \mathrm{s}^{-1}$. The figure illustrates the seismograms recorded at the deep sensors. Across all components the surface wave effect is not dominant.

Fig. 13 is the spectrum for the seismograms illustrated in Fig. 12. Unlike the spectrum in Fig. 11, there is no strong peak in the spectrum in the lower frequency band. The following parameters can be extracted from the spectrum: seismic moment $=2.9 \times 10^{7} \mathrm{Nm}$, static stress drop $=0.01 \times 10^{5} \mathrm{~Pa}$ and corner frequency $=37 \mathrm{~Hz}$ and so the moment magnitude is -1.0 .

The period of the direct P- wave pulse was estimated to be $0.02 \mathrm{~s}$. This corresponds to a corner frequency of approximately $50 \mathrm{~Hz}$, which is in good agreement with the frequency domain estimate.

\subsection{Composite Focal Mechanisms}

To get an indication of the source mechanisms of the recorded microseismic events, the polarity of the P-wave first arrivals was studied. For purely tensile fracturing consistent with extension strain, a positive (outward from the event) P-wave first movement is expected in all directions. A double-couple shear fracture would result in four zones in the azimuth and dip angle space of a stereographic projection: two positive zones and two negative zones.

Analysis into the focal mechanisms at Navachab was carried out on a dataset that consisted of five 7-seismogram events that were recorded $12^{\text {th }}-21^{\text {st }}$ July 2004 and located within the same region of the mine. The focal mechanism for a single seismic event could not be analysed as the seismic array does not provide complete three dimensional coverage of any event. These seismic events were located using all $\mathrm{P}$ - wave and at least $2 \mathrm{~S}$-wave arrivals and originate from deep below the seismic network.

The focal mechanism of the events was analyzed by observing the positions of polarities on a stereograph. Each point on the stereograph represents the polarity of the first, most dominant swing on the seismogram, recorded at a specific sensor. Only the polarities of the z-components were used, as the orientations of the two horizontal components on all sensors are unknown.

The dataset used for this analysis contained mostly seismograms where the polarity of the most dominant swing was fairly obvious (see Fig. 14a). However occasionally there were seismograms where the polarity was not obvious (see Fig. 14b). The first seismogram in Fig. 14b illustrates that the first weak P- wave arrival results in a negative swing and so the polarity of the first, most dominant swing can be judged as either positive or negative. Two stereographs were then plotted. These included all known polarities as well as the undefined polarities. These undefined polarities were plotted as positive in one stereograph and negative in another. The stereograph with the negative polarities illustrated a clear distinction between positive and negative regions. (See Fig. 15).

Fig. 15 indicates the presence of two negative polarities in the positive region of the stereograph. These seismograms were investigated and were found to come from sensors 8 and 14. Sensor 8 is located approximately $10 \mathrm{~m}$ from a free surface of the pit and sensor 14 is $11 \mathrm{~m}$ below the surface. Both sensors are good candidates for recording strong surface wave effects, which may distort the recorded signal.

The dashed line in Fig. 15 represents a portion of the nodal plane. This selection excludes the possibilities of reverse dip- 


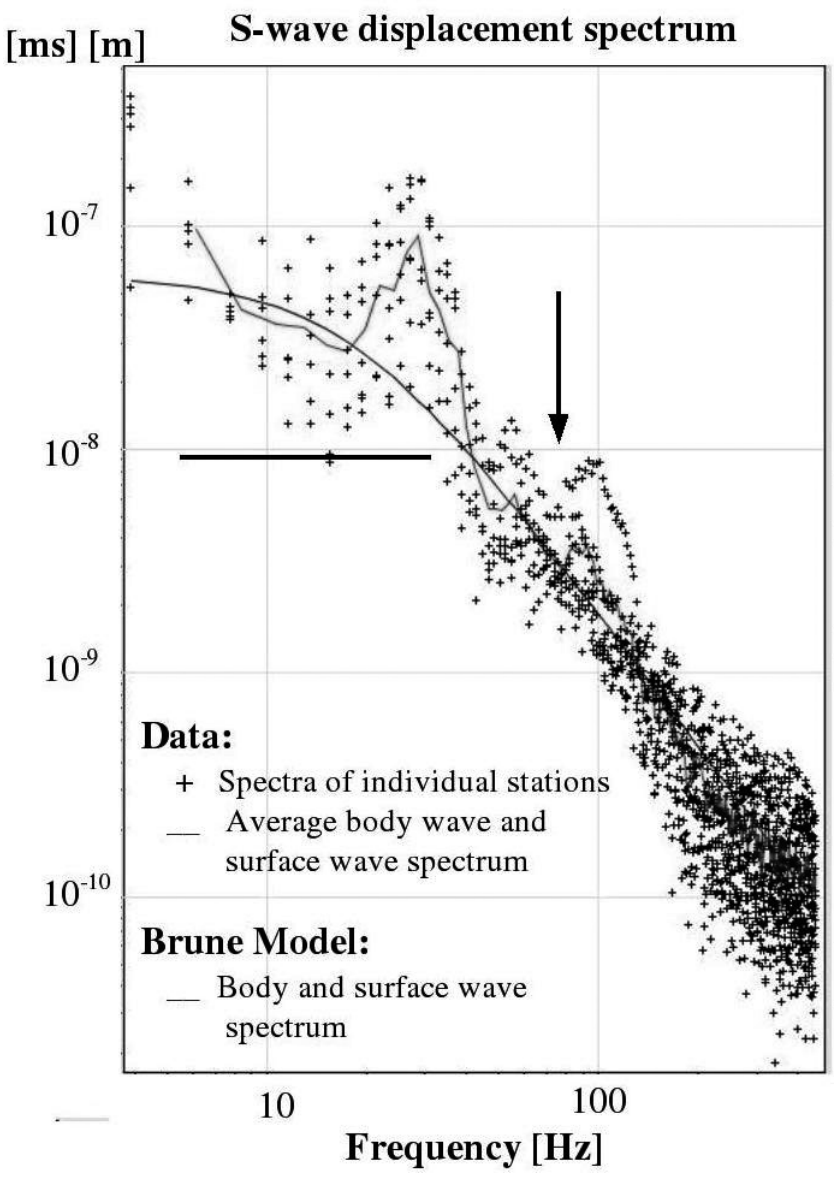

FIG. 11 S-wave and surface pulse spectrum for a seismic event that was recorded on 21 July 2004. The amplification of the signal between $10 \mathrm{~Hz}-30 \mathrm{~Hz}$ is associated with the surface wave pulse. Further inspection of this spectrum reveals that the contributions from sites 8 and 14 lie above the average spectrum. The black horizontal lie represents the spectral level of the body wave and the vertical arrow represents the corresponding corner frequency

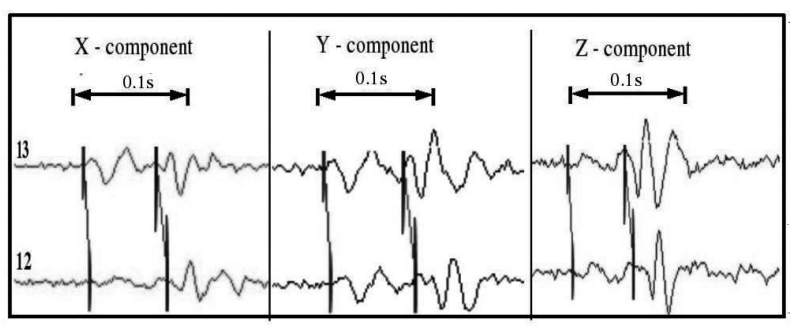

FIG. 12 Seismograms recorded by sensors 12 and 13 for an event on the 21 July 2004 at $14 \mathrm{~h} 33$ with the following peak ground velocity $\left[\mathrm{mm}^{\left.-\mathrm{s}^{-1}\right]:}\left(13,2.2 \times 10^{-3}\right)\right.$ and $(12$, $\left.1.9 \times 10^{-3}\right)$

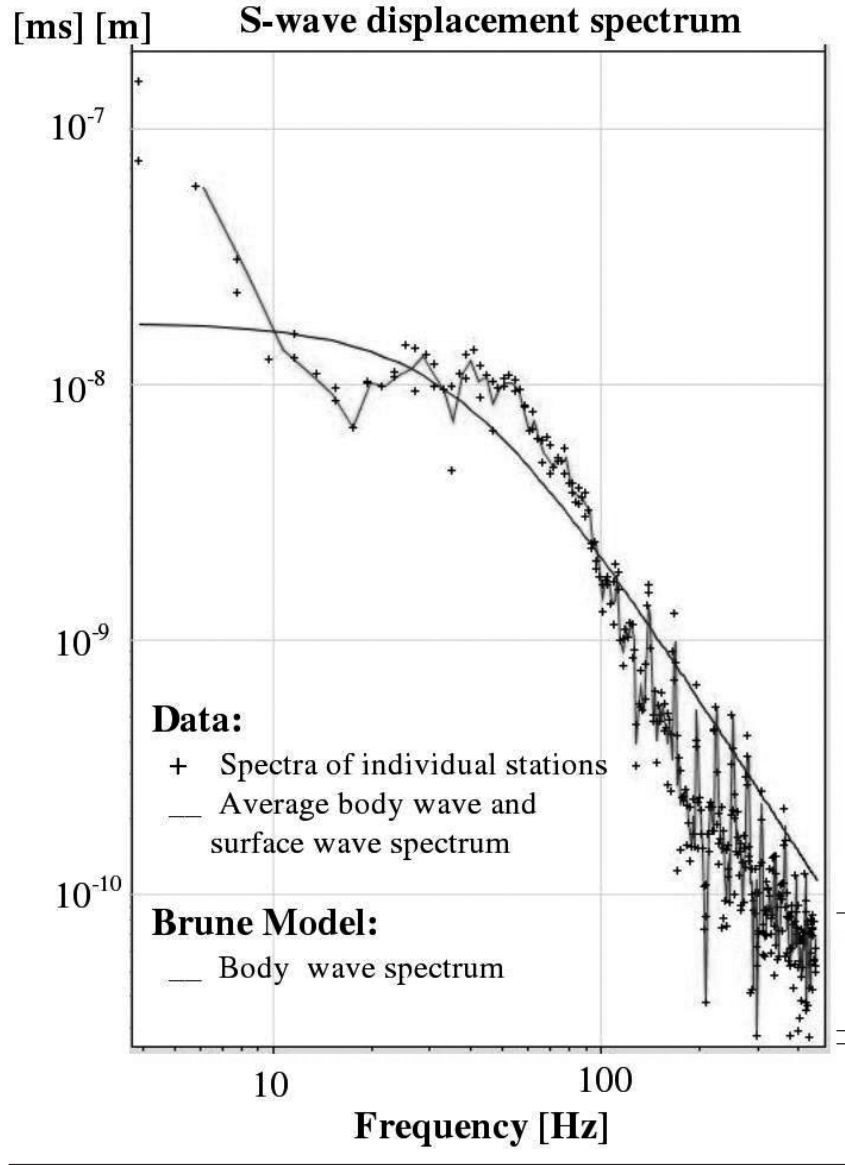

FIG. 13 S-wave spectra for seismograms recorded by the deep sensors for an event recorded on 21 July 2004

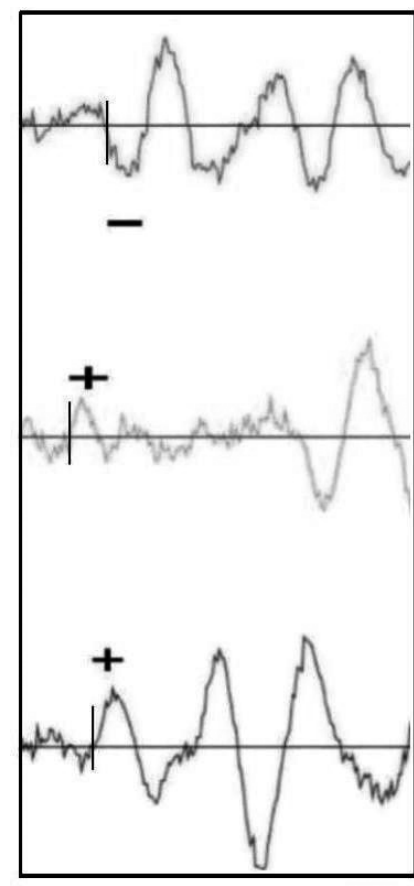

(a)

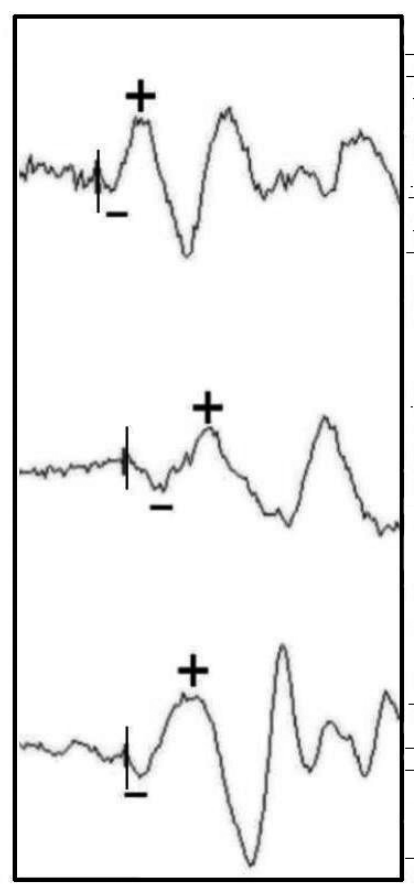

(b)
FIG. 14 (a) Obvious polarity: A seismogram used in the focal mechanism analysis illustrating polarities and (b) Obscure polarity: A seismogram used in the focal mechanism analysis illustrating polarities, illustrating the problem in selecting the correct polarity 
slip and normal dip-slip as focal mechanisms for this data set. One possible focal mechanism could be oblique-motion with a strong strike slip.

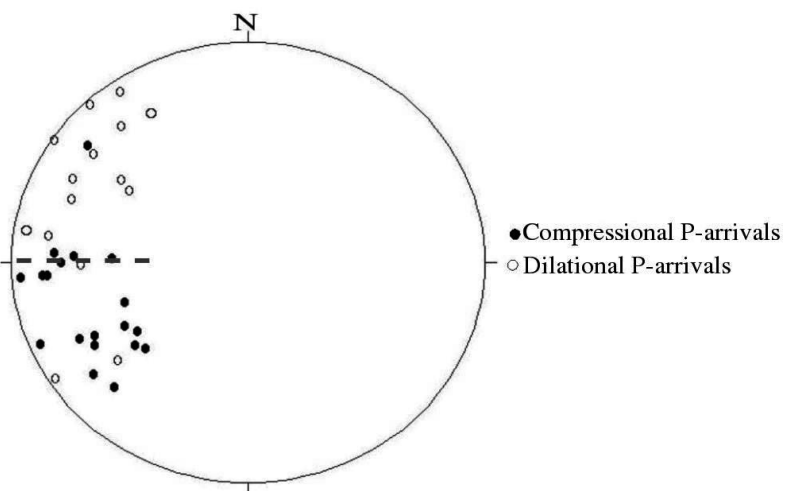

Equal area projection - Lower hemisphere

FIG. 15 P-wave first motions obtained from five 7-seismogram seismic events. These events locate in the southern region of the bottom of the Navachab pit. The stereograph illustrates the lower hemisphere equal - area projection of the focal sphere

The seismic events used in our analysis are strong events that originate in different places deep within the rockmass beneath the pit. Since the mechanisms of the selected seismic events are similar (see Fig. 15), we conclude that a composite focal mechanism approach can be used as a tool in this environment. Analysis into the focal mechanism of individual seismic events was inconclusive due to insufficient data. Preliminary analysis indicates that the focal mechanism of smaller seismic events that locate closer to the seismic array in the slope is not the same mechanism as the deeper events.

\section{SPECTRAL ANALYSIS OF SEISMIC DATA RECORDED AT SANDSLOOT}

The seismic events selected for this analysis are typical and representative of the events recorded in the eastern regions of the Sandsloot pit, June 2004. All selected events were recorded by four seismic sensors. The distances between the source and the sensors are a few hundred meters. The objective of this section is to analyse the high frequency asymptote of the displacement spectra. Usually, the displacement spectra of a seismic source is modelled with a constant low frequency level, corner frequency and a high frequency asymptote, $f^{-k}$.

The S-wave attenuation is calculated using the high frequency asymptote of the stacked displacement spectra. The start of the high frequency asymptote was defined using an estimate of the corner frequency obtained from uncorrected stacked spectra. The frequency band between the estimated corner frequency and the upper end of the spectra was then used to calculate the quality factor, $Q$. This attenuation of the $\mathrm{S}$-wave was obtained independently for each seismic event. Brune's model with a high frequency asymptote of $\mathrm{k}=2$ was first assumed. The obtained value for $Q$ was found to be too small and unrealistic. Furthermore, attempts with a weakly frequency dependent quality factor did significantly improve matters. The high frequency asymptote of $\mathrm{k}=3$ was then tested. In this case the high frequency asymptotes of the displacement spectra were matched with $Q$ values varying from 300 to 450 . Fig. 16 shows some stacked displacement spectra corrected for distance and attenuation with $Q=400$. Fig. 16 illustrates that $f^{-3}$ fits the stacked spectra more accurately than the commonly used $f^{-2}$.

It is well known that the parameterisation of observed spectra is not unique. Different models of site effect, attenuation and seismic source can be used to reproduce the observed spectra.

The high frequency asymptotic behaviour is related to the singularity of the time function and is controlled by source rise time and its stopping phase. The spectra corresponding to the rise time will have a high frequency asymptote decay that is proportional to $\mathrm{k}=3$ (Aki and Richards, 2002). The stopping phase will have a high frequency asymptotic decay that will vary between $\mathrm{k}=2$ and $\mathrm{k}=3$ depending on the model of the stopping phase. A possible interpretation of this high frequency asymptote is given by Boatwright (1982). Boatwright considers two variations of the seismic source model. The modelled source increases from a fixed starting point with a uniform high rupture velocity. This rupture could stop abruptly or gently. The $f^{-3}$ spectral decay represents
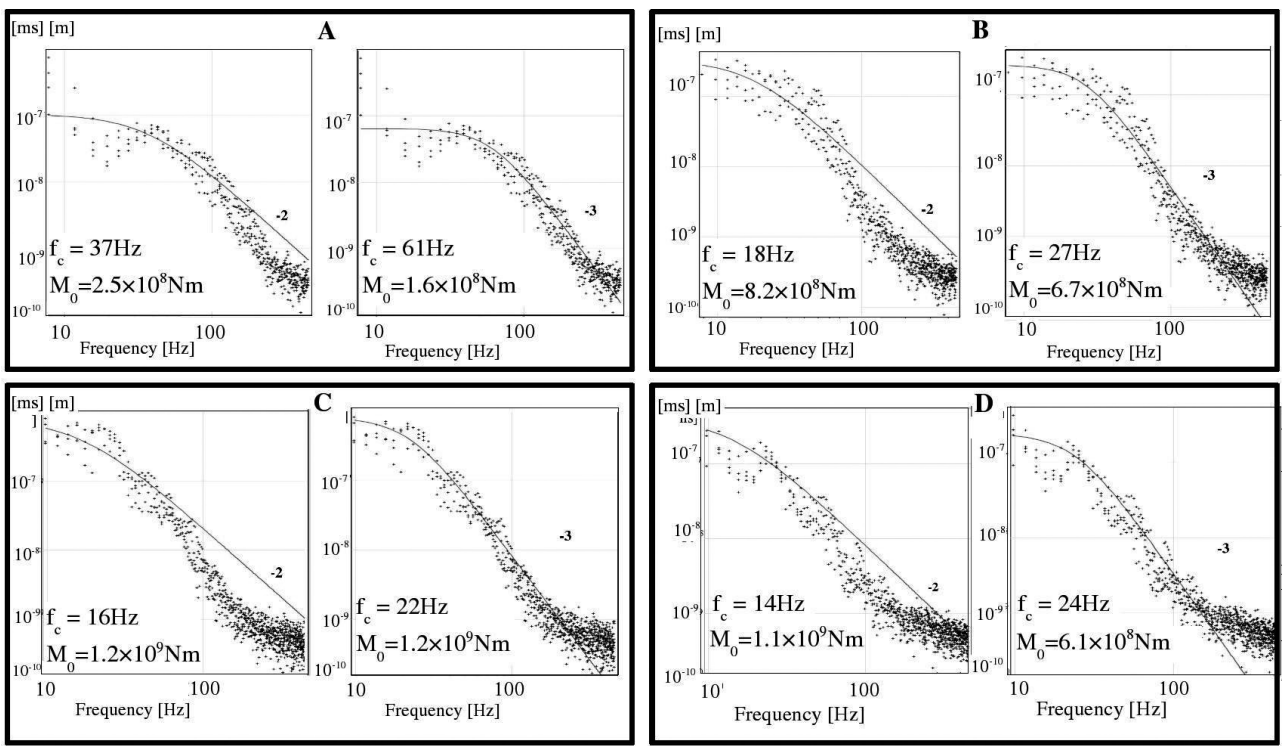

FIG. 16 S-wave displacement spectra for 4 seismic events A-D recorded at Sandsloot in June 2004 corrected for distance and attenuation with $Q=400$. Each pair of spectra represents a single event. Spectra on the left have a Brune model fit to the data using a $f^{-2}$ decay, whereas the spectra on the right have a better fit of $f^{3}$. Note the differences in corner frequency from the different model fits. The static stress drops for the model with $\mathrm{k}=3$ are as follows: (A) $0.3 \times 10^{5} \mathrm{~Pa}$, (B) $0.1 \times 10^{5} \mathrm{~Pa},(\mathrm{C}) 0.1 \times 10^{5} \mathrm{~Pa},(\mathrm{D}) 0.06 \times 10^{5} \mathrm{~Pa}$ 
a gradual arrest of rupture while the $f^{-2}$ spectral decay represents an abrupt arrest of rupture. Brune's model with a high decay of $\mathrm{k}=2$ is most frequently used in earthquake seismology. This model assumes that the abrupt stopping phase dominates the high frequency asymptote. However it appears that the model with $\mathrm{k}=3$ may be more suitable for the data used in this analysis. The low stress environment of open pits could possibly be related to the gradual slowing down of the rupture process.

\section{ANALYSIS OF OPEN PIT MICROSEISMICITY}

A plot of cumulative number of seismic events recorded in the Navachab eastern slope from April 2002 until January 2004 shows 2 distinct periods of increased microseismic activity: October 2002 to January 2003 and June to September 2003 - Fig. 17.

The general form of the plot in Fig. 17 is very similar to the cumulative amount of rock removed from the bottom of the pit during this time - Fig. 18. This close correlation between levels of fracturing in the slope and mining at pit bottom is reasonable. Rainfall, typically between November and March, does not appear to influence slope fracturing to the same degree.

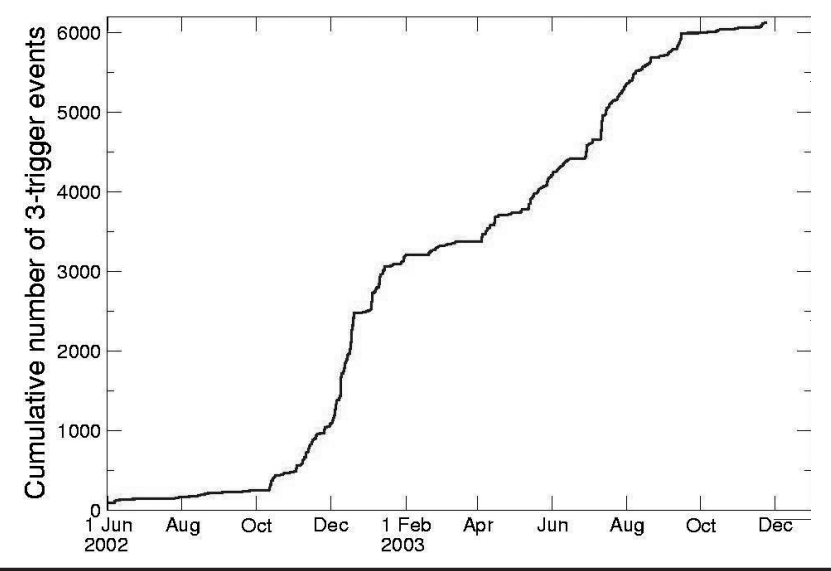

FIG. 17 Cumulative number of seismic events recorded at Navachab between June 2002 and January 2004. There is a close correlation between levels of fracturing in the slope and mining at pit bottom

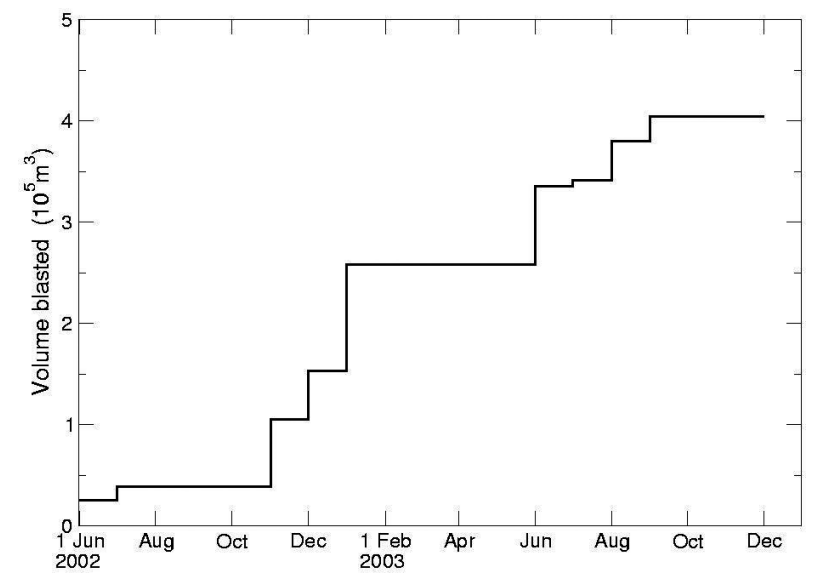

FIG. 18 Cumulative volume of rock extracted from the pit bottom from June 2002 to December 2003

One of the most widely used forms of geotechnical data is surface movements of the pit slopes, obtained by routine surveys of surface targets. This data for targets that moved significantly during July 2002 to February 2003 is presented in Fig. 19. At around the beginning of December 2002, a group of targets were identified by the mine geotechnical engineers as moving and being a possible cause for alarm. The position of these targets is indicated in Fig. 20.

Since the scalar seismic moment and source location is estimated for each seismic event, a standard expression for the static displacement field may be used (Aki and Richards, 2002). The average radiation pattern is computed assuming fracture orientations such that the wall moves outwards, and never inwards, with each event. No assumptions are made regarding specific mechanisms of the seismicity. After a scaling constant to account for free-surface effects and slope geometry was calibrated from the survey data, the inferred co-seismic displacement for any point on the highwall surface may be computed from the seismic data. Contours of this are shown in the Fig. 21 for each of the last 6 months of 2002.

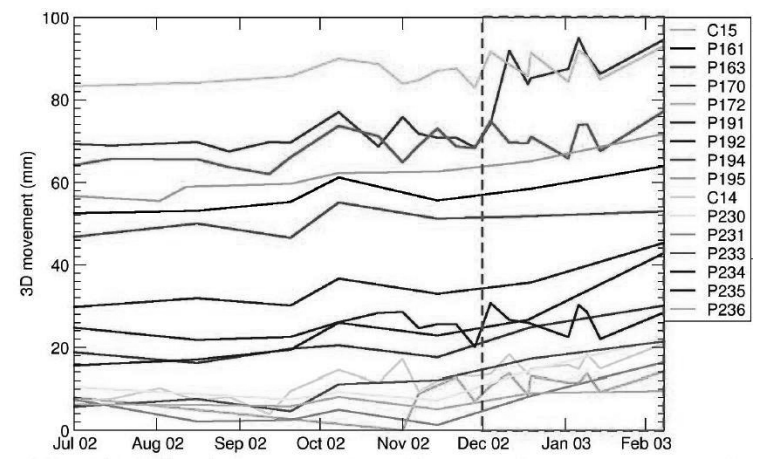

FIG. 19 Displacement data for moving targets on the eastern highwall from July 2002 to February 2003. While the data is typically very noisy, the mine geotechnical engineer detected a consistent movement starting during the $1^{\text {st }}$ week of December 2002

The spatial correspondence between the bulging areas of the slope indicated by seismic data and the actual moving areas is striking. Rather interesting is the advance indication provided by microseismic data: approximately 45 days in this case. This advance is seen more clearly by computing inferred surface movements from seismic data for a single point target and comparing this with actual recorded surface movements. This is shown in Fig. 22. The time lag is probably the result of the rheology introduced into the slope rockmass by the numerous bedding planes and other heterogeneities and would thus vary from mine to mine. Of course, the time lag is also a function of the location of seismic events - events close to the surface of the slope would result in smaller time lags than deeper events.

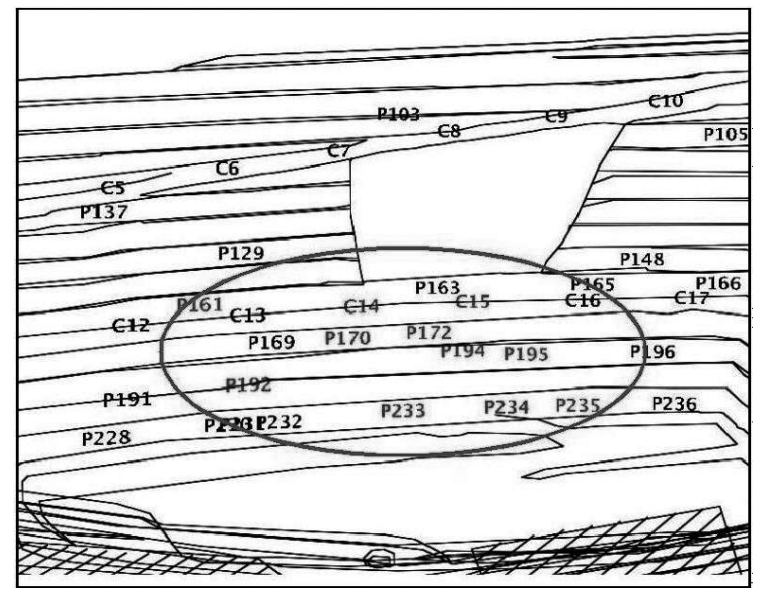

FIG. 20 Survey targets on the eastern highwall. The targets that show significant movement from the beginning of December 2002 are circled 
A similar example may be found in the seismic data recorded at Union Reefs mine in Australia. Here surface prisms were surveyed every week during the last half of 2002 and this data is presented in Fig. 23. After a software artefact at the beginning of November has been ignored, it is clear that significant movement was observed on a number of the prisms towards the end of November 2002. The position of the most active prisms is shown in Fig. 24 and indicates consistent movement in the upper central part of the western slope.

During this time microseismicity was being recorded at Union Reefs. Since source parameters like co-seismic inelastic deformation are being estimated for each recorded and located seismic event, surface deformations may be inferred in the manner outlined previously. Contours for the 7 months from May to November 2002 are presented in Fig. 25. Again a close spatial correlation is observed between the surface movements indicated from microseismic data and the moving prisms. As before, the microseismic data indicates significant surface movements some time before the movements are observed on surface. In this case, a 30 day advance indication was possible.

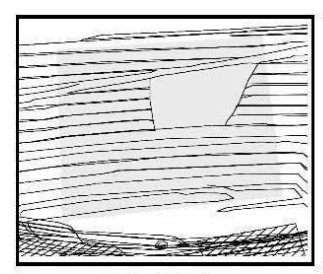

July 2002

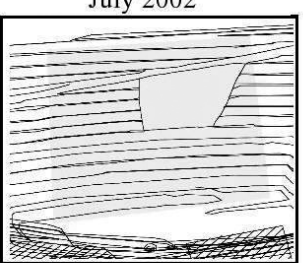

September 2002

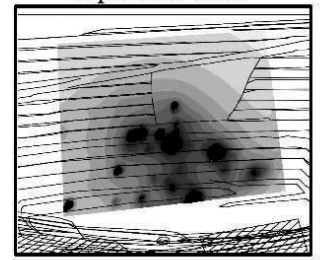

November 2002

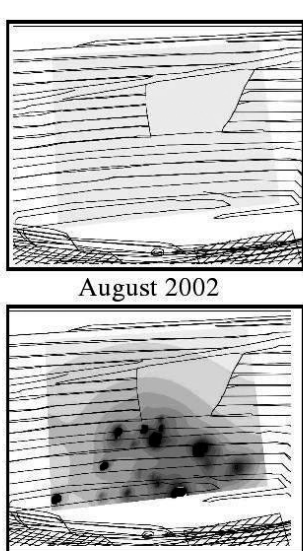

October 2002

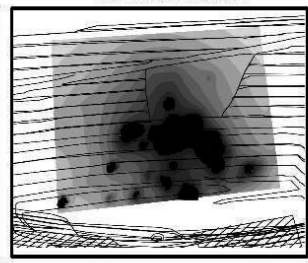

December 2002

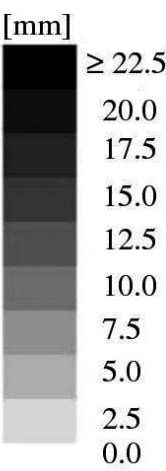

FIG. 21 Surface movements inferred from microseismic data recorded during the months of July-December 2002. Note that during July to September, the maximum inferred surface movements were less than $1 \mathrm{~mm}$ and so no contours are drawn

\section{CONCLUSIONS}

Seismic monitoring carried out at Navachab and Union Reefs has shown that routine microseismic monitoring of open pit slopes is now feasible. Technological advances have resulted in lightning-resistant intelligent seismic stations, while the speed of the internet now means that seismological processing and analysis can now be carried out at a remote central facility.

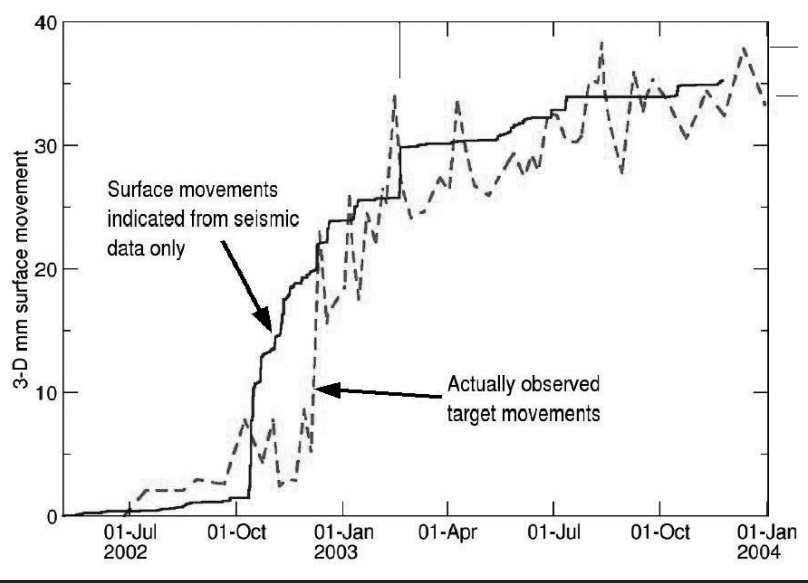

FIG. 22 Inferred surface movements at target P170 computed from microseismic data (solid line) compared with actual survey data (dashed line). The qualitative similarity is striking, with a time advance of about $\mathbf{4 5}$ days provided from microseismic data

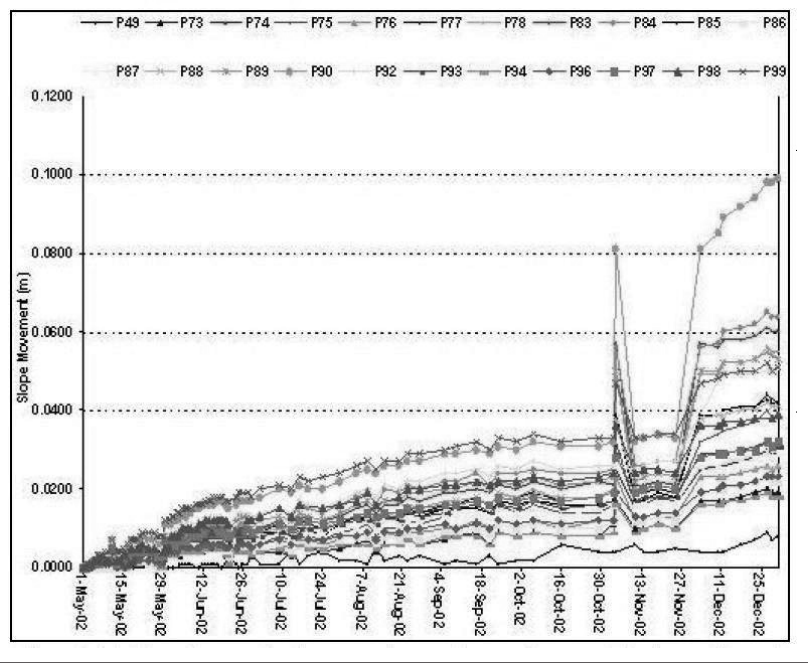

FIG. 23 Surface deformation data from Union Reefs mine. The spike in data around the beginning of November is a result of an error in the survey data analysis software

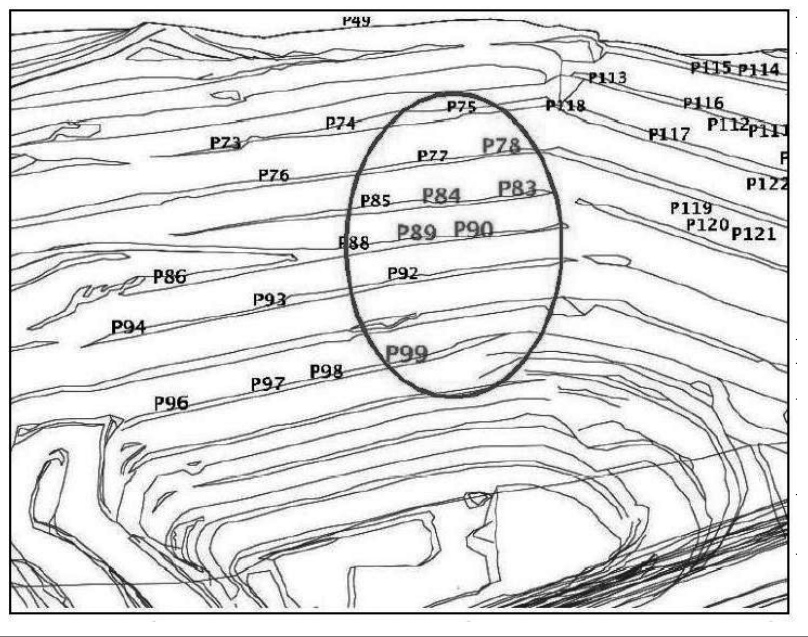

FIG. 24 The survey prisms on the western slope of the Crosscourse pit at Union Reefs, Australia. At the end of November 2002 significant movement was observed on the prisms circled, in the central upper part of the slope 


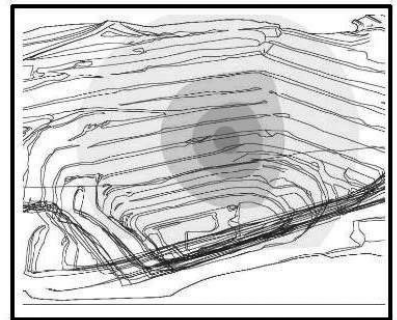

May 2002

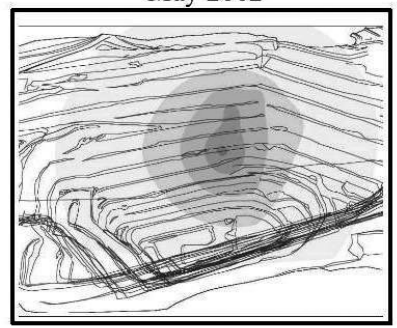

July 2002

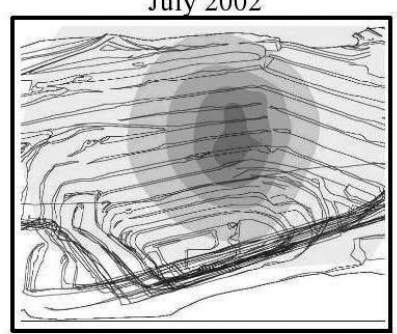

September 2002

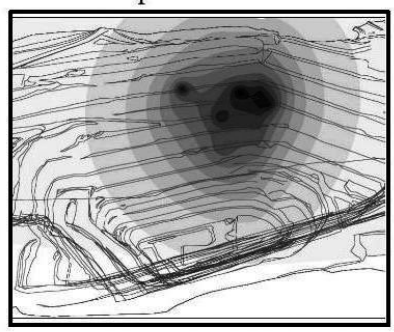

November 2002

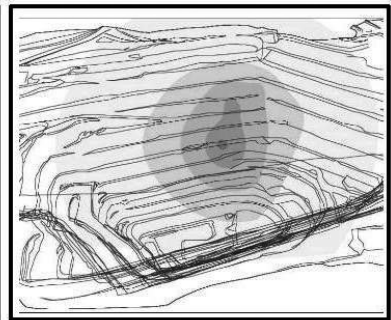

June 2002

August 2002

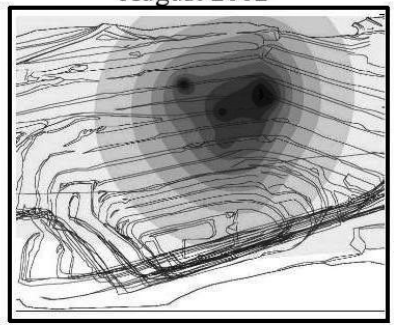

October 2002

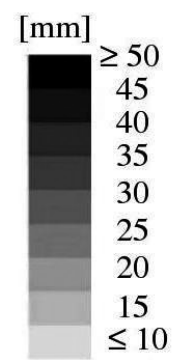

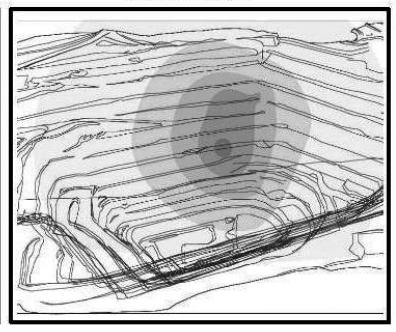

FIG. 25 Surface movements inferred from microseismic data recorded during the months of July-November 2002

Simple 2-D elastic modelling of the Navachab slope indicates that failure of intact rock for this slope is not likely with either the extension strain or shear strain mechanisms. Since microseismicity is nevertheless being recorded here, it can be concluded that geological structures are playing an important role. The directions of major principal stresses from modelling coincide with the J1 joint set and thus it is probably that these joints are fracturing. More generally, it is noted that reconciliation between modelled zones of high stress and zones of recorded fracturing is important for a more complete understanding of the evolution of the slope.

An algorithm for detection of statistically significant planes of weakness using microseismic data has been implemented. The most significant plane in the Navachab data is very similar to the J1 set, providing further evidence that these features are dominating slope stability here.

Microseismic monitoring can give an indication whether a particular known geological structure is seismically active or not. If many seismic events locate on or near the structure, then it is likely that the structure is slipping. Indeed, planes of weakness defined by seismic events may indicate previously unknown geological structures that may be then confirmed by other geotechnical means.

Calibration blasts can illuminate the effects of complex geology on recorded seismic data in open pit environments.
The free surfaces in this environment appear to have a strong influence on the seismic spectra and should be taken into account for accurate estimates of seismic source parameters. A composite focal mechanism approach seems to be valid for the deeper events at Navachab and is useful in constraining possible fault plane orientations. Seismogram spectra recorded at Sandsloot show that the usually assumed $f^{-2}$ high frequency decay is not necessarily the best choice for open pit fractures and care should be exercised in computing source parameters. The seismic events recorded at both the Navachab and Sandsloot open pits appear to be characterized by very low static stress drops of the order of $10^{4} \mathrm{~Pa}$, much lower than those typically recorded underground.

From the seismic event locations and analysis of source parameters, it is possible to infer surface movements resulting from this microseismicity. Surface movement is recorded by conventional surveying of prisms or by slope radar. Comparison between these two forms of data has revealed that the seismic data may be able to indicate regions of surface movement some 30-45 days before these movements are seen on the surface. This advance time would depend on rock properties and the locations of the recorded seismic events.

The usefulness of microseismic monitoring stems from the fact that cracks are located by the system wherever they occur and so a 3-D picture of the rockmass is obtained, unlike the 1D or 2-D data obtained with conventional surface monitoring. It is not so much a short-term slope-failure warning technique (such as a trip-wire), but rather a system for longer-term understanding of where and when rock failures are occurring. As such, the technique is complementary to the latest surface surveying techniques.

At this time, microseismic systems have been installed in mines in Australia, Namibia and South Africa for routine monitoring of slope stability. It is clear that this relatively new application of seismic monitoring has the potential to improve the assessment of slope stability in open pit mines.

\section{ACKNOWLEDGMENTS}

This work would not have been possible without the support and enthusiasm (not to mention cold beer) of the Navachab gold mine, particularly Graham Bell (of SRK Consulting), Frik Badenhorst and Jan Walkers, Gary Davies and Chris Fowers of Union Reefs gold mine as well as Des Mossop, Megan Little and Kelly Lachenicht of PPL. Discussions with Peter Terbrugge and Dr Oskar Steffen of SRK Consulting and Prof Dick Stacey of the University of the Witwatersrand are also gratefully acknowledged.

\section{REFERENCES}

Aki, K. and Richards, P.G. (2002) Quantitative Seismology, University Science Books, USA.

van Aswegen, G., Durrheim, R.J. and Ortlepp, W.D. (2000) Dynamic rockmass response to mining, Proceedings of the 5th International Symposium on Rockburst and Seismicity in Mines, South African Institute of Mining and Metallurgy.

Boatwright, J. (1982) A Dynamic model for far -field acceleration, Bull. Seism. Soc. Am. Pp. 1049-1068.

Brune, J. (1970) Tectonic Stress and Spectra of Seismic Shear Waves from Earthquakes, J. Geophys. Res. 75 pp. 4997-5009.

ISS International (2001) StandAlone QS technical specification, available from http://www.issi.co.za/ftp/manuals/saqsinfo.pdf.

Itasca Consulting Group (2000) FLAC (Fast Lagrangian Analysis of Continua) Version 4.0.

Mendecki, A.J. (ed.) (1997) Seismic Monitoring in Mines, Chapman and Hall, Cambridge.

Popov, E.P. (1990) Engineering Mechanics of Solids, Prentice-Hall International Editions.

Sainsbury, D.P., Pierce, M.E. and Lorig, L.J. (2003) Two and ThreeDimensional Numerical Analysis of Interaction between Open Pit Slope Stability and Remnant Underground voids, Proceedings of the 5th Large Open Pit Conference, Australian Institute of Mining and Metallurgy. 
Stacey, T.R., Xianbin, Y., Armstrong, R. and Keyter, G.J. (2003a) New slope stability considerations for deep open pit mines, The Journal of The South African Institute of Mining and Metallurgy.

Stacey, T.R., Terbrugge, P.J., Keyter, G.J. and Xianbin, Y. (2003b) Extension Strain - A New Concept in Open Pit Slope Stability and its Use in the Explanation of Two Slope Failures, Proceedings of the 5th Large Open Pit Conference, Australian Institute of Mining and Metallurgy. 